\title{
Correlation and Prognostic Significance of Electrocardiography, Echocardiography and Troponin in Patients Admitted with NSTEMI
}

Dileep Kumar ( $\nabla$ dileep_dewani2011@yahoo.com )

National Institute of Cardiovascular Diseases

Tahir Saghir

National Institute of Cardiovascular Diseases

Kamran Ahmed Khan

National Institute of Cardiovascular Diseases

Muhammad Naeem Mengal

National Institute of Cardiovascular Diseases

Khalid Naseeb

National Institute of Cardiovascular Diseases

Khalid Iqbal Bhatti

National Institute of Cardiovascular Diseases

Musa Karim

National Institute of Cardiovascular Diseases

Kelash Rai

National Institute of Cardiovascular Diseases

Shahzad Khatti

National Institute of Cardiovascular Diseases

\section{Research Article}

Keywords: troponin, patients, mortality, myocardial, infarction, nstemi

Posted Date: June 22nd, 2021

DOI: https://doi.org/10.21203/rs.3.rs-433064/v1

License: (c) (i) This work is licensed under a Creative Commons Attribution 4.0 International License.

Read Full License 


\section{Abstract}

Background: Non ST segment elevation myocardial infarction (NSTEMI) is a clinical condition characterized by typical symptoms of myocardial ischemia along with electrocardiographic changes and a positive value of troponin. After presentation in emergency department these patients have their troponin I value and electrocardiography done. The echocardiography should also be performed in these patients. This study was conducted to determine the relationship between ECG, Echo and troponin and how prognostically these are relevant to each other along with their prognostic significance.

Results: This observational study was conducted at tertiary care cardiac hospital on 221 patients diagnosed with the NSTEMI. The most frequent finding on presenting ECG was ST depression in anterior leads (V1-V6) in 27.6\%. Median troponin I at presentation was $3.2 \mathrm{ng} / \mathrm{dl}$ and median ejection fraction was $45 \%$. Overall all-cause mortality rate at 6 -months was observed to be $8.6 \%$, re-infarction in $5 \%$, rehospitalization in $16.3 \%$, and heart failure in $25.3 \%$ was observed. However, mortality was higher for patients with baseline ECG findings of A-fib, generalized ST-depression, poor R-wave progression, Wellens sign, and T-wave inversion in inferior also mortality rate was relatively higher among patients with poor $(<30 \%)$ LVEF.

Conclusion: ECG and Echocardiography were prognostically significant and correlated better at 6 months. However Troponin lacks the association and prognostic significance at 6 months.

\section{Background}

Non ST-segment elevation myocardial infarction (NSTEMI) is a clinical condition characterized by typical symptoms of myocardial ischemia along with electrocardiographic changes and a positive value of troponin. After presentation in emergency department these patients have their troponin I value and electrocardiography done [1], echocardiography should also be considered in these patients. Furthermore, these investigations are helpful in risk stratification and for further decision making to undergo coronary intervention or to manage conservatively.

Although all these modalities have high impact on prognosis independently. However, there are no studies available which correlated altogether the ECG, Echo and Troponin. Moreover, admitting ECG findings are valuable in the assessment of risk and predict the prognosis in patients with NSTEMI [2, 3]. ECG could have numerous findings including ST segment depression, T wave inversion and most of the time ECG could be normal or have nonspecific findings. Previous studies have shown that ST depression have adverse short term and long term cardiovascular outcomes [4,5]. Additionally, Troponin is a biomarker which is preferable in the setting of acute coronary syndrome and differentiates from unstable angina. Although, management strategy is same for both the conditions and there are multiple studies on the prognostic value of troponin in NSTEMI [6-11]. Subsequently, Echocardiography is the basic tool to further evaluate the patients with NSTEMI to recognize segmental wall motion abnormalities $[12,13]$. And 
left ventricular ejection fraction along with other parameters. This would be helpful in deciding the further management plan.

Therefore, studies like this which could associate all the basic modalities in NSTEMI and jointly signify the outcome in these patients is needed for further risk stratification.

This study was conducted to determine the relationship between ECG, Echo and troponin and how prognostically these are relevant to each other along with their prognostic significance. Such information would help physicians to categorize the patients further with their management plan.

\section{Methods}

This observational study was conducted at the tertiary care cardiac hospital of Pakistan from august 2019 to august 2020 . The sample size of this study was calculated by using the standard online equation and this was approximated to be around 300 patients. All the patients diagnosed with NSTEMI were enrolled in this study. The patients who were not diagnosed with NSTEMI and who did not give consent were excluded from this study. Electrocardiography, troponin was the basic tool along with echocardiography.

This study was commenced after the approval of ethical review committee of the hospital. Oral consent was taken and documented from all the enrolled patients. Baseline features including age, gender, risk factors such as diabetes, hypertension, obesity, smoking, and family history of premature coronary artery disease were documented on the designed questionnaire along with the vitals of the patients.

Electrocardiography was performed to see any particular ischemic findings and troponin value was also categorized. On echocardiography, left ventricular ejection fraction was divided into two categories of LVEF $<40 \%$, and LVEF $>40 \%$. These all findings were noted to correlate with each other and to determine the outcome. All the patients were followed up to 6 months and outcomes such as all-cause mortality, reinfarction, re-hospitalization, and heart failure were recorded.

Data analysis was performed with the help of IBM SPSS version 21, descriptive summary such as mean $\pm S D$, median [interquartile range (IQR)], and range (maximum - minimum) were calculated for continuous variables and frequency and percentages were calculated for categorical variables.

\section{Results:}

A total of 221 patients with NSTEMI were included, out of which $76.9 \%$ (170) were male and mean age was $57.63 \pm 10.48$ years with $20.4 \%$ (45) above 60 years of age. A majority (84.6\%) of patients were in killip class I at presentation and only $2.7 \%$ (6) patients were in killip class III and no patients was in killip class IV. The commonest co-morbid condition was hypertension (82.4\%) followed by diabetes $(41.6 \%)$ and smoking (26.2\%). Sedentary lifestyle was reported by $24.9 \%(55)$ of the patients. The most frequent finding on presentation ECG was ST depression - anterior (27.6\%) followed by T wave inversion - 
anterior (14\%), 12.2\% (27) patient had non-specific changes, and 16.3\% (36) patients had normal ECG. Median troponin I at presentation was $3.2 \mathrm{ng} / \mathrm{dL}[7.3-1.2 \mathrm{ng} / \mathrm{dL}$ ] ranging over 0.06 to $50 \mathrm{ng} / \mathrm{dL}$. Median ejection fraction was $45 \%$ [ $55-35 \%$ ] with range of 15 to $70 \%$. Demographic characteristics, baseline troponin I level, ECG changes, echocardiographic findings are presented in Table 1.

Distribution of troponin I by various ECG changes are presented in Figure 1. Proportion of patients in $4^{\text {th }}$ quartile (>7.30 ng/dL) was more prominent for the patients with baseline ECG findings of poor R-wave, ST depression - generalized, and ST-depression inferior, while, lower quartile distribution of troponin I was more commonly observed with non-specific ECG changes, normal ECG, T-wave inversion - inferior, ST-depression lateral, and ST-depression - anterior.

Distribution of ejection fraction by various ECG changes are presented in Figure 2. Poor LVEF (\%) can be seen with ECG finding of Afib, poor R-wave, ST-depression - anterior, and ST-depression inferior. LEVF was in normal range for most of the patients with normal ECG and ST-depression -lateral.

Correlation between troponin I and left ventricular ejection fraction against various ECG changes are presented in Figure 3. High troponin I levels and low LVEF was found to be related with ECG changes of ST-depression - generalized, poor R-wave, and Afib. While, low troponin I levels and high LVEF were observed against ECG changes of ST-depression - lateral, T-wave inversion - anterior, - inferior, and lateral, Wellens sign, and normal ECG.

Adverse cardiac event rate at 6-months for various ECG changes, troponin I quartiles, and ejection fraction categories are presented in Table 2. Overall all-cause mortality rate at 6-months was observed to be $8.6 \%$, re-infarction rate of $5 \%$, re-hospitalization in $16.3 \%$, and heart failure rate of $25.3 \%$ was observed. All-cause mortality rate was relatively higher for patients with baseline ECG findings of Afib, STdepression - generalized, poor R-wave, Wellens sign, and T-wave inversion - inferior also mortality rate was relatively higher among patients with poor $(<30 \%)$ LVEF. The relationship between mortality rate and troponin I level is non-conclusive.

Re-infarction rate was also relatively higher for the patients with ECG findings of Afib, Wellens sign, and ST-depression generalized. Re-infarction rates are surprisingly tends to remain higher for lower quartile of troponin I. Poor LVEF was also observed to be associated with higher re-infarction rate. Heart failure rate was observed to be related to poor LVEF and baseline ECG findings of Afib, ST-depression - generalized, poor R-wave, T-wave inversion inferior. However, relationship of troponin I and heart failure rate remain inconclusive.

\section{Discussion}

The current study shows one of the biggest and recent evaluation of patients with NSTEMI in the cotemporary era according to the presentation of ECG findings along with Troponin level and echocardiography from a large tertiary care center of Pakistan. The most significant finding on ECG in the present study was ST depression and T wave inversions in anterior leads that collectively accounted for 
41.6\% (ST depression anterior 27.6\%, anterior T wave inversion $14 \%$ ) of total patients diagnosed with NSTEMI. This was in contrast from one of the large study by Patel et al. that showed no ischemic changes $(60.2 \%)$ as the most frequent finding [14]. However, our results were in line with a sub-analysis from the GUSTO-Illb (Global Use of Strategies to Open Occluded Arteries in Acute Coronary Syndromes) study, where out of 12,142 patients, $35.1 \%$ had ST-depression, versus $22.4 \%$ with T-wave inversion [15]. A further greater frequency of ST depression was noted in the ICTUS (Invasive versus Conservative Treatment in Unstable Coronary Syndromes) study, in which approximately $50 \%$ of the population had STdepression at first presentation [16]. Moreover, ECG findings of generalized ST segment depression and poor $\mathrm{R}$ wave progression were better correlated with the high troponin value and low ejection fraction and resulted in poor prognosis at 6 months. All-cause mortality was higher in atrial fibrillation with NSTEMI was 33.3\%, followed by generalized ST segment depression (28.6\%), Wellens sign (16.7\%), poor R wave progression (16.7\%). Heart failure, re infarction and re-hospitalization was high in atrial fibrillation, generalized ST depression and in poor progression of $\mathrm{R}$ wave followed by other findings. Previous data is scarce from the studies which can correlate the ECG with troponin value and echocardiography.

In this study, Mean range of troponin was $6.35+-8.59$ and the mean ejection fraction was $43.02 \pm 12.13 \%$. Troponin level is not a good predictor of mortality and results showed in this study are inconclusive. However, in a study of Gerber Yariv et al: showed upper and lower Troponin T tertiles at 30 days were 5.8 (95\% confidence interval [Cl], 1.4-10.2) for death, 5.2 (95\% Cl, 0.2-10.3) for recurrent ischemic event, and $6.9(95 \% \mathrm{Cl}, 1.4-12.4)$ for heart failure [17].

This study revealed the significance of low ejection fraction $<30 \%$ resulted in overall mortality of $35 \%$ in comparison to the $\mathrm{EF}$ of $30-45$ and $>45 \%$ had $9.6 \%$ and $1.2 \%$ respectively. There is no such study which linked ejection fraction and other echo parameters with outcomes including mortality in NSTEMI patients. Heart failure and re-infarction was also found to be significant with low EF of $60 \%$ and $25 \%$ respectively.

ECG, Echo and troponin altogether categorize the patients according to associated risk and will be detrimental in making a management plan and helpful for clinicians in decision making.

This study has few Limitations as this was the single center study and smaller volume of sample that could not be generalized. Therefore, a multicenter large volume study is required to generalize to the whole population.

\section{Conclusion}

Electrocardiography along with echocardiography has a better prognostic significance at 6 months. However, troponin considered as of high importance could not associate with ECG and Echo in terms of predictive value. Furthermore, ECG and ECHO are correlated with each other in patients with NSTEMI.

\section{Abbreviations}


ECG: electrocardiography, Echo: echocardiography, EF: ejection fraction, Afib: atrial fibrillation, LVEF: left ventricular ejection fraction

\section{Declarations}

Conflict of interest: None

Funding: None

Disclaimers: None

\section{References}

1. Amsterdam EA, Wenger NK, Brindis RG, Casey DE, Ganiats TG, Holmes DR, Jaffe AS, Jneid H, Kelly RF, Kontos MC, Levine GN. 2014 AHA/ACC guideline for the management of patients with non-STelevation acute coronary syndromes: a report of the American College of Cardiology/American Heart Association Task Force on Practice Guidelines. J Am Coll Cardiol. 2014;64:e139-228.

2. Savonitto S, Ardissino D, Granger CB, Morando G, Prando MD, Mafrici A, Cavallini C, Melandri G, Thompson TD, Vahanian A, Ohman EM. Prognostic Value of the Admission Electrocardiogram in Acute Coronary Syndromes. JAMA. 1999;281:707-13. https://doi.org/10.1001/jama.281.

3. Cannon CP, McCabe CH, Stone PH, Rogers WJ, Schactman M, Thompson BW, Pearce DJ, Diver DJ, Kells C, Feldman T, Williams M. The Electrocardiogram Predicts One-Year Outcome of Patients With Unstable Angina and non-Q Wave Myocardial Infarction: Results of the TIMI III Registry ECG Ancillary Study. Thrombolysis in Myocardial Ischemia. J Am Coll Cardiol. 1997;30:133-40.

4. Savonitto S, Cohen MG, Politi A, Hudson MP, Kong DF, Huang Y, Pieper KS, Mauri F, Wagner GS, Califf RM, Topol EJ. Extent of ST-segment depression and cardiac events in non-ST-segment elevation acute coronary syndromes. Eur Heart J. 2005;26:2106-2113.

5. Krone RJ, Greenberg H, Dwyer EM Jr, Kleiger RE, Boden WE. Long-term prognostic significance of ST segment depression during acute myocardial infarction: the multicenter Diltiazem Postinfarction trial research group. J Am Coll Cardiol. 1993;22:361-367.

6. Ottani F, Galvani M, Nicolini FA, Ferrini D, Pozzati A, Di Pasquale G, Jaffe AS. Elevated cardiac troponin levels predict the risk of adverse outcome in patients with acute coronary syndromes. Am Heart J. 2000;140:917-27.

7. Aviles RJ, Askari AT, Lindahl B, Wallentin L, Jia G, Ohman EM, Mahaffey KW, Newby LK, Califf RM, Simoons ML, Topol EJ. Troponin T levels in patients with acute coronary syndromes, with or without renal dysfunction. N Engl J Med. 2002;346:2047-52.

8. Yan AT, Yan RT, Tan M, Chow CM, Fitchett D, Stanton E, Langer A, Goodman SG. Troponin is more useful than creatine kinase in predicting one-year mortality among acute coronary syndrome patients. Eur Heart J. 2004;25:2006-201. 
9. Prasad A, Rihal CS, Lennon RJ, Singh M, Jaffe AS, Holmes DR Jr. Significance of periprocedural myonecrosis on outcomes after percutaneous coronary intervention: an analysis of preintervention and postintervention troponin T levels in 5487 patients. Circ Cardiovasc Interv. 2008;1:10-9.

10. Lindahl B, Venge P, James $S$. The new high-sensitivity cardiac troponin T assay improves risk assessment in acute coronary syndromes. Am Heart J. 2010;160:224-9.

11. Mills NL, Churchhouse AM, Lee KK, Anand A, Gamble D, Shah AS, Paterson E, MacLeod M, Graham C, Walker S, Denvir MA. Implementation of a sensitive troponin I assay and risk of recurrent myocardial infarction and death in patients with suspected acute coronary syndrome. JAMA. 2011;305:1210-6.

12. Roffi M, Patrono C, Collet JP, Mueller C, Valgimigli M, Andreotti F, Bax JJ, Borger MA, Brotons C, Chew DP, Gencer B. 2015 ESC Guidelines for the management of acute coronary syndromes in patients presenting without persistent ST-segment elevation: Task Force for the Management of Acute Coronary Syndromes in Patients Presenting without Persistent ST-Segment Elevation of the European Society of Cardiology (ESC). Eur Heart J. 2016;37:267-315.

13. Neumann FJ, Sousa-Uva M, Ahlsson A, Alfonso F, Banning AP, Benedetto U, Byrne RA, Collet JP, Falk V, Head SJ, Jüni P. 2018 ESC/EACTS Guidelines on myocardial revascularization. Eur Heart J. 2019;40(2):87-165.

14. Patel JH, Gupta R, Roe MT, Peng SA, Wiviott SD, Saucedo JF. Influence of presenting electrocardiographic findings on the treatment and outcomes of patients with non-ST-segment elevation myocardial infarction. Am J Cardiol. 2014;113:256-61.

15. Savonitto S, Ardissino D, Granger CB, Morando G, Prando MD, Mafrici A, Cavallini C, Melandri G, Thompson TD, Vahanian A, Ohman EM. Prognostic value of the admission electrocardiogram in acute coronary syndromes. JAMA. 1999;281:707-13.

16. de Winter RJ, Windhausen F, Cornel JH, Dunselman PH, Janus CL, Bendermacher PE, Michels HR, Sanders GT, Tijssen JG, Verheugt FW. for the invasive versus conservative treatment in unstable coronary syndromes (ICTUS) investigators. Early invasive versus selectively invasive management for acute coronary syndromes. N Engl J Med. 2005;353:1095-104.

17. Gerber Y, Jaffe AS, Weston SA, Jiang R, Roger VL. Prognostic Value of Cardiac Troponin T After Myocardial Infarction: A Contemporary Community Experience. Mayo Clin Proc. 2012;87:247-54.

\section{Tables}

Table 1: Demographic characteristics, baseline troponin I level, ECG changes, echocardiographic findings 


\begin{tabular}{ll} 
Characteristics & Total \\
\hline Total $(\mathbf{N})$ & 221 \\
\hline Gender & \\
\hline Male & $76.9 \%(170)$ \\
\hline Female & $23.1 \%(51)$ \\
\hline Age (years) & $57.63 \pm 10.48$ \\
\hline$\leq 50$ years & $28.1 \%(62)$ \\
\hline 51 to 65 years & $51.6 \%(114)$ \\
\hline$>65$ years & $20.4 \%(45)$
\end{tabular}

\section{KILLIP class at presentation}

$\begin{array}{ll}\text { I } & 84.6 \%(187) \\ \text { II } & 12.7 \%(28) \\ \text { III } & 2.7 \%(6) \\ \text { IV } & 0 \%(0)\end{array}$

\section{Risk factors}

\begin{tabular}{ll}
\hline Hypertension & $82.4 \%(182)$ \\
\hline Diabetes & $41.6 \%(92)$ \\
\hline Smoking & $26.2 \%(58)$ \\
\hline Dyslipidemia & $11.8 \%(26)$ \\
\hline Family history of CAD & $10.4 \%(23)$ \\
\hline Obesity & $7.7 \%(17)$ \\
\hline Sedentary lifestyle & $24.9 \%(55)$ \\
\hline Troponin I (ng/dL) & \\
\hline Mean \pm SD & $6.35 \pm 8.59$ \\
\hline Median [IQR] & $3.2[7.3-1.2]$ \\
\hline Range (Max - Min) & $50-0.06$ \\
\hline Ejection fraciton (\%) & \\
\hline Mean \pm SD & $43.02 \pm 12.13$ \\
\hline Median [IQR] & $45[55-35]$ \\
\hline
\end{tabular}




\begin{tabular}{ll} 
Range (Max - Min) & $70-15$ \\
\hline ESD & \\
\hline Mean \pm SD & $34.9 \pm 7.47$ \\
\hline Median [IQR] & $33[38-29]$ \\
\hline Range (Max - Min) & $66-22$ \\
\hline EDD & \\
\hline Mean \pm SD & $47.82 \pm 6.11$ \\
\hline Median [IQR] & $48[51-44]$ \\
\hline Range (Max - Min) & $69-33$ \\
\hline Baseline ECG & \\
\hline ST depression: Anterior & $27.6 \%(61)$ \\
\hline ST depression: Inferior & $5.4 \%(12)$ \\
\hline ST depression: Lateral & $5.4 \%(12)$ \\
\hline ST depression: Gen & $3.2 \%(7)$ \\
\hline T wave inversion: Anterior & $14 \%(31)$ \\
\hline T wave inversion: Inferior & $3.2 \%(7)$ \\
\hline T wave inversion: Lateral & $0.9 \%(2)$ \\
\hline Poor R wave & $5.4 \%(12)$ \\
\hline Hyperacute T wave & $2.3 \%(5)$ \\
\hline Wellens sign & $2.7 \%(6)$ \\
\hline AFib & $1.4 \%(3)$ \\
\hline Non specific & $12.2 \%(27)$ \\
\hline Normal & $16.3 \%(36)$ \\
\hline
\end{tabular}

$\mathrm{CAD}=$ coronary artery diseases, $\mathrm{SD}=$ standard deviation, $\mathrm{IQR}=$ interquartile range

Table 2: Adverse cardiac event rate at 6-months against ECG changes, troponin I, and ejection fraction 
Total 6-months outcome

(N)

\section{Overall}

ECG

\begin{tabular}{|c|c|c|c|c|c|}
\hline ST depression: Ant & 61 & $4.9 \%(3)$ & $4.9 \%(3)$ & $16.4 \%(10)$ & $27.9 \%(17)$ \\
\hline ST depression: Inf & 12 & $0 \%(0)$ & $8.3 \%(1)$ & $8.3 \%(1)$ & $8.3 \%(1)$ \\
\hline ST depression: Lat & 12 & $8.3 \%(1)$ & $0 \%(0)$ & $25 \%(3)$ & $33.3 \%(4)$ \\
\hline ST depression: Gen & 7 & $28.6 \%(2)$ & $14.3 \%(1)$ & $42.9 \%(3)$ & $42.9 \%(3)$ \\
\hline T wave inversion: Ant & 31 & $6.5 \%(2)$ & $9.7 \%(3)$ & $25.8 \%(8)$ & $22.6 \%(7)$ \\
\hline T wave inversion: Inf & 7 & $14.3 \%(1)$ & $0 \%(0)$ & $14.3 \%(1)$ & $42.9 \%(3)$ \\
\hline T wave inversion: Lat & 2 & $0 \%(0)$ & $0 \%(0)$ & $50 \%(1)$ & $50 \%(1)$ \\
\hline Poor R wave & 12 & $16.7 \%(2)$ & $0 \%(0)$ & $0 \%(0)$ & $41.7 \%(5)$ \\
\hline Hyperacute T wave & 5 & $0 \%(0)$ & $0 \%(0)$ & $0 \%(0)$ & $0 \%(0)$ \\
\hline Wellens sign & 6 & $16.7 \%(1)$ & $16.7 \%(1)$ & $16.7 \%(1)$ & $16.7 \%(1)$ \\
\hline AFib & 3 & $33.3 \%(1)$ & $33.3 \%(1)$ & $66.7 \%(2)$ & $66.7 \%(2)$ \\
\hline Non specific & 27 & $11.1 \%(3)$ & $3.7 \%(1)$ & $14.8 \%(4)$ & $22.2 \%(6)$ \\
\hline Normal & 36 & $8.3 \%(3)$ & $0 \%(0)$ & $5.6 \%(2)$ & $16.7 \%(6)$ \\
\hline \multicolumn{6}{|l|}{ Trop I } \\
\hline 1st Quartile $(\leq 1.20)$ & 61 & $14 \%(8)$ & $10.5 \%(6)$ & $21.1 \%(12)$ & $31.6 \%(18)$ \\
\hline $\begin{array}{l}\text { 2nd Quartile ( } 1.20 \text { to } \\
3.20)\end{array}$ & 12 & $3.7 \%(2)$ & $1.9 \%(1)$ & $11.1 \%(6)$ & $16.7 \%(9)$ \\
\hline $\begin{array}{l}\text { 3rd Quartile (3.20 to } \\
7.30)\end{array}$ & 12 & $7.3 \%(4)$ & $7.3 \%(4)$ & $14.5 \%(8)$ & $25.5 \%(14)$ \\
\hline 4th Quartile (>7.30) & 7 & $9.1 \%(5)$ & $0 \%(0)$ & $18.2 \%(10)$ & $27.3 \%(15)$ \\
\hline \multicolumn{6}{|l|}{ EF } \\
\hline$<30 \%$ & 61 & $35 \%(7)$ & $15 \%(3)$ & $25 \%(5)$ & $60 \%(12)$ \\
\hline 30 to $45 \%$ & 12 & $9.6 \%(11)$ & $5.2 \%(6)$ & $22.6 \%(26)$ & $33 \%$ (38) \\
\hline$>45 \%$ & 12 & $1.2 \%(1)$ & $2.3 \%(2)$ & $5.8 \%(5)$ & $7 \%(6)$ \\
\hline
\end{tabular}

Figures
$\mathrm{Re}-$

infarction hospitalization

$5 \%(11)$

$16.3 \%(36)$
$25.3 \%(56)$
All-cause

mortality

Heart

Failure

$8.6 \%(19)$

$16.3 \%(36)$

.




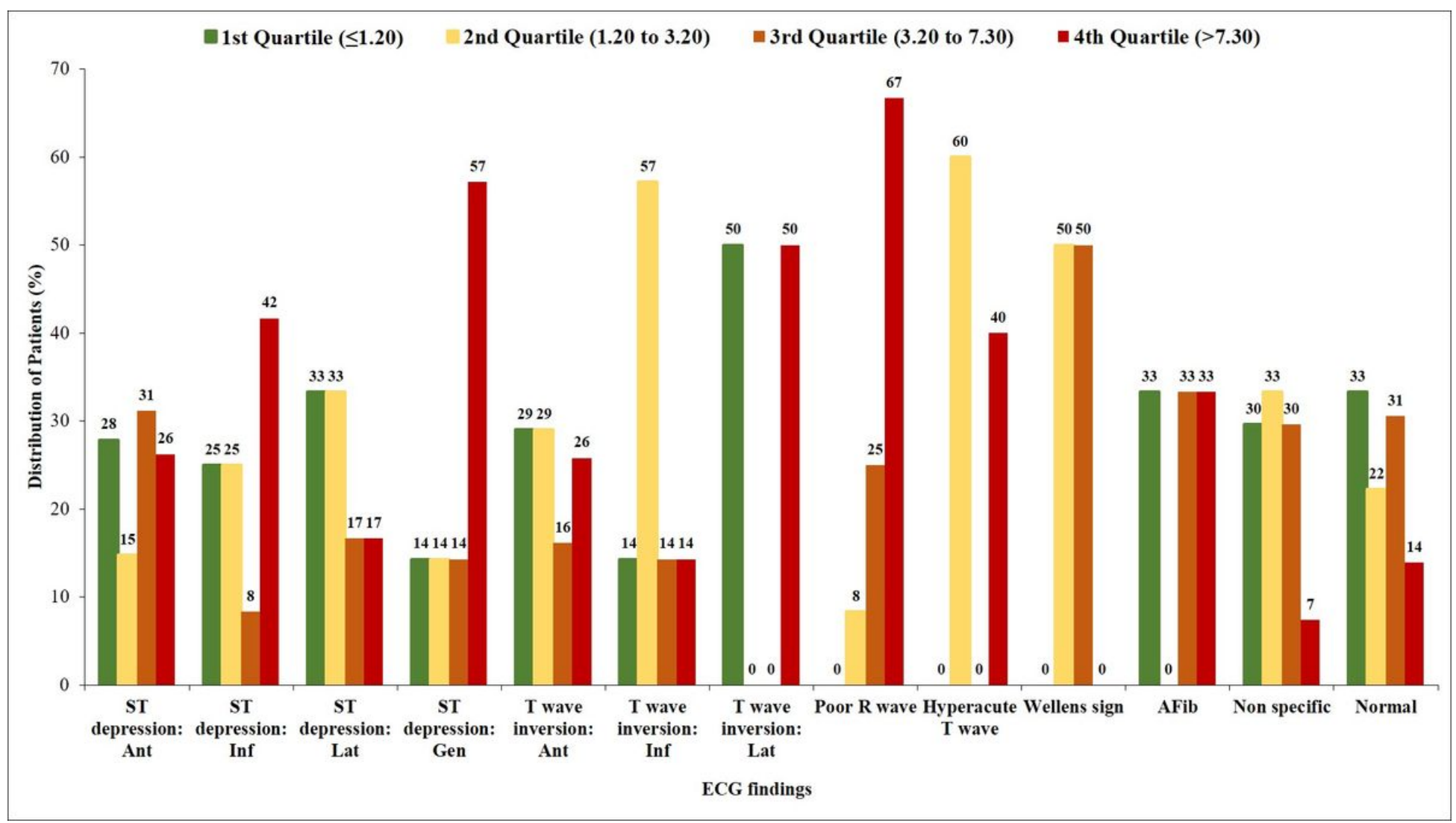

Figure 1

Distribution of troponin I by various ECG changes

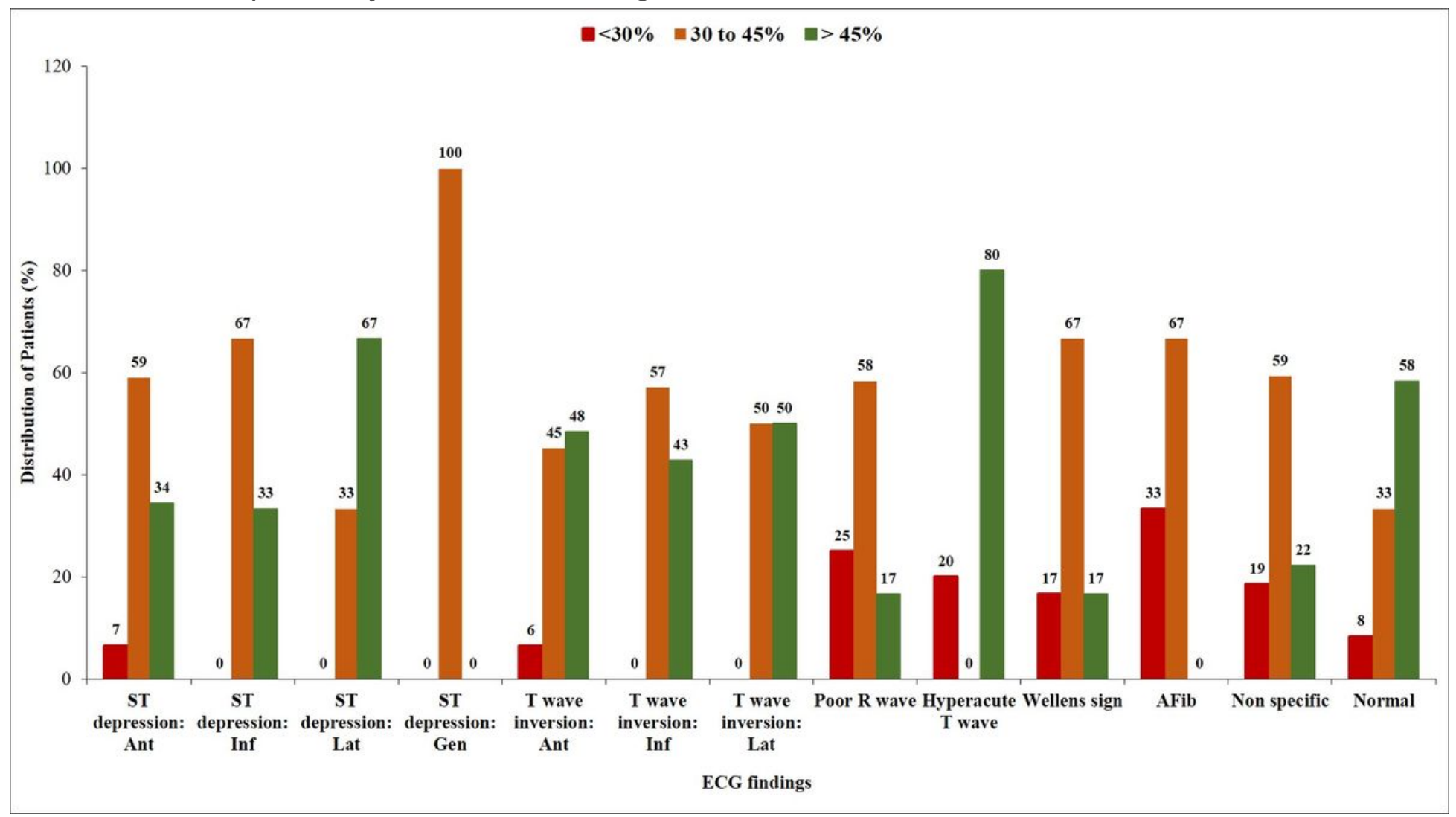

Figure 2 
Distribution of ejection fraction by various ECG changes

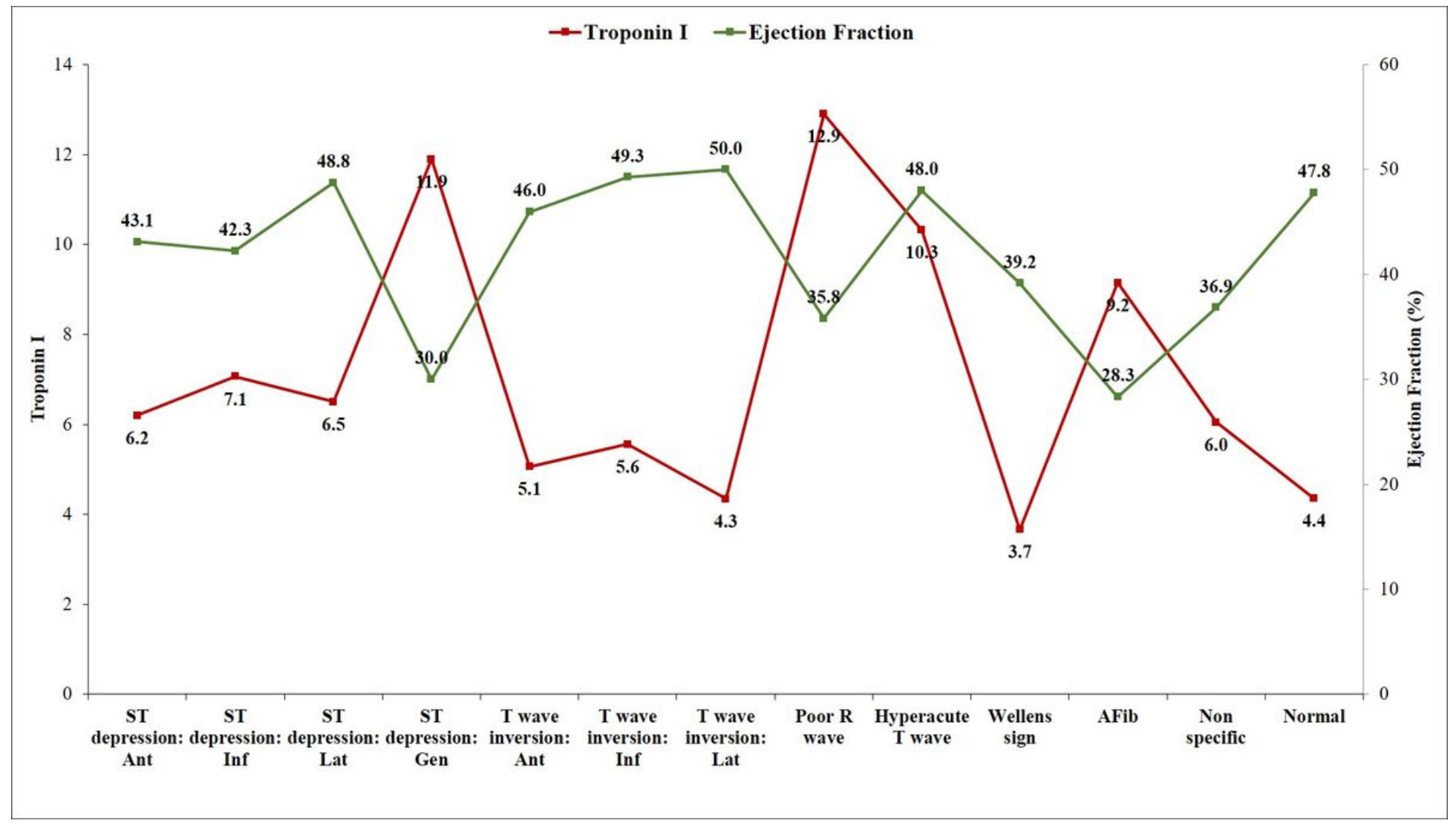

\section{Figure 3}

Correlation between troponin I and left ventricular ejection fraction against various ECG changes 